\title{
MicroRNAs as Biomarkers and Therapeutic Targets in Heart Failure
}

\author{
István Adorján Szabó ${ }^{1}$ Atilla Frigy²* \\ 1. Department of Physiopathology, University of Medicine, Pharmacy, Science and Technology of Târgu Mureș, Romania \\ 2. Department of Internal Medicine IV, University of Medicine, Pharmacy, Science and Technology of Târgu Mureș, Romania
}

Heart failure still represents a real challenge both in everyday practice and research, due to the complex issues related to its pathogenesis and management. Humoral biomarkers have emerged in the last decades as useful tools in the diagnosis, risk stratification and guiding the treatment of heart failure. These molecules are related to different pathological and adaptive processes, like myocardial injury, neurohormonal activation and cardiac remodeling, their most widespread representatives being the natriuretic peptides (e.g. NT-proBNP). The role of altered gene expression and transcription as the basis of myocardial structural and functional changes in heart failure is largely recognized. MicroRNAs (miRNAs) are non-coding RNAs which have a major role in post-transcriptional gene expression by interfering with messenger RNA molecules. Our short review summarizes the molecular biology of miRNAs and their possible role as biomarkers in the diagnosis and prognosis of heart failure. Furthermore, the therapeutical perspectives conferred by these molecules are also presented.

Keywords: miRNA, biomarkers, heart failure

Received 7 June 2019 / Accepted 29 June 2019

\section{Introduction}

In heart failure (HF), structural and functional cardiac changes affect the systolic and/or diastolic function of the heart, leading to low cardiac output and increased filling pressures. The resulting global hypoperfusion and pulmonary and systemic congestion trigger the well-known symptoms and signs of HF (dyspnea, fatigue, edema) [1].

The complex pathophysiological processes behind HF are accompanied with altered synthesis (over- or underproduction), or de novo appearance of certain humoral compounds, molecules, called cardiac biomarkers. These substances can be used in the diagnosis and risk stratification of HF. Furthermore, they can be useful also in the follow-up of patients and in the guiding of therapy. Theirs most frequently used representatives are the natriuretic peptides (e.g., N-terminal prohormone brain natriuretic peptide, NT-proBNP) [2].

In many fields of cardiac pathology (e.g., certain arrhythmias, cardiomyopathies, etc.) the investigation and clarification of genetic background (e.g., channellopaties, sarcomere protein gene mutations) is a usual and mandatory part of management. Also, background genetic changes could serve as novel biomarkers with prognostic and therapeutical value. In this regard, microRNAs (miRNAs) a type of non-coding RNAs are promising molecules as biomarkers in the setting of HF. Furthermore, the study of miRNAs could provide a better understanding of molecular mechanisms which play role in the pathogenesis of cardiac morpho-functional changes causing HF [3].

In the followings, we present a short and comprehensive review of the main issues related to circulating miRNAs as biomarkers and future therapeutic targets in HF.

\section{Molecular biology of miRNAs}

miRNAs make of the group of non-coding RNAs, together with transfer RNAs, ribosomal RNAs, small nuclear RNAs, small nucleolar RNAs, Piwi-interacting RNAs and long non-coding RNAs. The main role of these molecules is to regulate gene expression by interfering with the functioning and translation of messenger RNAs (mRNAs).

miRNAs are encoded in the genome, and based on their genomic location are classified as intergenic (with own promoters), exonic and intronic (co-expressed or transcribed in reverse orientation of the host genes) types. Transcription by the RNA-polymerase II or III (in fewer cases), results in the primary miRNA, named pri-miRNA (with hairpin shape), which contains 65 nucleotides. In the presence of exportine- 5 the pri-miRNA is transported to the cytoplasm, where it is processed by the cytoplasmic RNase III (Dicer family), resulting the mature miRNA (with length of 18 to 24 nucleotides), which integrates in the miRNA-induced silencing complex (miRISC). The miRISC, due to its miRNA content can recognize specific target mRNAs and can determine their translational silencing (gene expression regulation at post-transcriptional level). The miRNA molecule binds to the untranslated parts of the mRNA, triggering its destabilization and degradation, thus, selectively inhibiting protein synthesis $[4,5]$.

At cellular level, miRNAs influence many processes, like differentiation (fig. 1), proliferation, apoptosis, metabolism and ageing. They could be involved in many pathological pathways, like fibrosis or remodelling, due to their under- or overexpression [6]. A searchable database of known and characterized miRNAs is available at the website www.mirbase.org. 


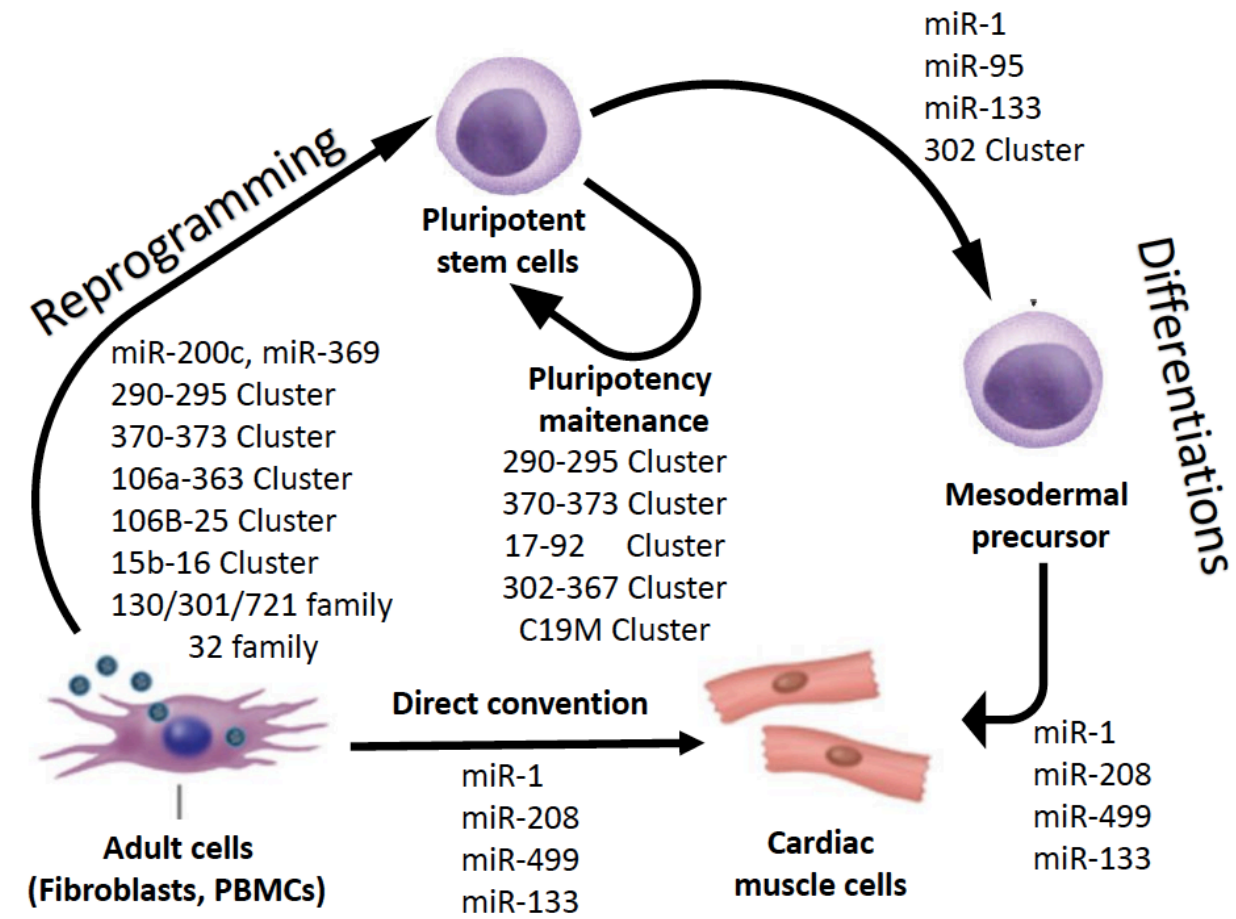

âFig. 1. Representation of the involvement of different miRNAs in cardiac cell differentiation

\section{miRNAs as diagnostic and prognostic biomarkers in heart failure}

The changes in the expression of different classes of miRNAs related to various cardiovascular diseases indicate their role in pathogenesis. This confer them utility as potential, novel biomarkers and therapeutical targets. miRNAs could play an important role in the progression of heart diseases even from the beginning, from the initiation of the pathophysiological mechanisms [7, 8]. Table 1 presents the types of miRNAs and their biological actions, with impact on the development of morpho-functional changes leading to HF [9].

Generally, circulating miRNAs could be considered as adequate biomarkers in HF because: a) they can be obtained relatively easily, rapidly and efficiently, and are very stable in the sample; b) certain miRNA profiles are highly specific for certain tissues and pathophysiological processes; c) have the advantage of not suffering post-translational changes [10].

Up- and down-regulation of diverse types of miRNAs, closely related to pathogenesis of HF, could serve as diagnostic and prognostic biomarkers (Table 2) [11, 12]. Many studies demonstrated the presence of a specific circulating miRNA profile in patients with HF. Marfella et al. evaluat- ed a panel of 84 miRNAs previously associated with structural abnormalities of the heart, finding a lower expression of 24 circulating miRNAs in patients with HF. Also, in responders to cardiac resynchronization therapy an increase of 19 types of miRNAs were observed [13]. Apart from some exceptions, several studies mention miR- $423-5 p$ as a

Table 2 miRNAs and their potential value as biomarkers in heart failure

\begin{tabular}{|c|c|c|c|}
\hline Role & MicroRNA & $\begin{array}{l}\text { Regulation type } \\
\text { in HF }\end{array}$ & $\begin{array}{c}\text { Relation with other } \\
\text { biomarkers }\end{array}$ \\
\hline \multirow[t]{4}{*}{ Diagnostic } & $\begin{array}{c}\text { miR-22 } \\
\text { miR-92b } \\
\text { miR-320a } \\
\text { miR-423-5p }\end{array}$ & Up & + NT-proBNP \\
\hline & $\begin{array}{l}\text { miRNA-26b-5p } \\
\text { miRNA-29a-3p } \\
\text { miRNA-30e-5p } \\
\text { miRNA-92a-3p }\end{array}$ & Down & - NT-proBNP \\
\hline & $\begin{array}{l}\text { miR-499 } \\
\text { miR-208b }\end{array}$ & $\begin{array}{l}\text { Elevated after } \\
\text { acute HF }\end{array}$ & $+\mathrm{cTnT}$ \\
\hline & $\begin{array}{c}\text { miR-1 } \\
\text { miR-21 } \\
\text { miR133a } \\
\text { miR-208 }\end{array}$ & $\begin{array}{l}\text { Time dependent } \\
\text { changes after } \\
\text { AMI }\end{array}$ & without correlation \\
\hline Prognostic & miR-182 & Up & $\begin{array}{l}\text { superior to NT-proB- } \\
\text { NP in the prediction } \\
\text { of future cardiovas- } \\
\text { cular mortality }\end{array}$ \\
\hline
\end{tabular}

Table 1 MiRNAs and their biological actions, with (modulating) impact on the development of heart failure

\begin{tabular}{lc}
\hline Biological action & MiRNA type \\
\hline Pro-hypertrophic & $155,199 \mathrm{a}, 199 \mathrm{~b}, 19 \mathrm{a} / \mathrm{b}, 208 \mathrm{a}, 21,21-3 \mathrm{p}, 212 / 132,22,221,23 \mathrm{a}, 27 \mathrm{~b}, 30 \mathrm{a}, 328,350$ \\
$\begin{array}{l}\text { Anti-hypertrophic } \\
\text { Pro-fibrotic }\end{array}$ & $1,101,133,145,150,185,223,26 \mathrm{~b}, 30-3 \mathrm{p}, 34 \mathrm{a}, 378,9,98$ \\
$\begin{array}{l}\text { Anti-fibrotic } \\
\text { Pro-apoptotic }\end{array}$ & $125 \mathrm{~b}, 21$ \\
Anti-apoptotic & $1,140,146 \mathrm{~b}, 15 \mathrm{~b}, 17-5 \mathrm{p}, 181 \mathrm{a}, 195,210,26 \mathrm{a}, 30 \mathrm{~b}, 30 \mathrm{~d}, 34 \mathrm{a}, 497,539,92 \mathrm{a}$
\end{tabular}


useful biomarker associated with HF. In one of the earliest studies in this field, Tijsen et al. identified 6 miRNAs that were elevated in patients with HF, among them miR-423$5 p$ showing a strong association with the clinical diagnosis and the levels of BNP [14]. Various studies have suggested that miRNAs are able to differentiate diverse forms of HF, and could be used as novel biomarkers of HF with preserved ejection fraction $[15,16]$. However, miRNAs are not yet recommended by current expert opinions to be used as independent biomarkers in HF, because of the lack of data on large patient populations.

\section{miRNAs as therapeutic targets in heart failure}

As we stated above, recent data support, that miRNAs are involved in the onset and development of different pathophysiological pathways playing role in HF. The resulted new paradigm is about their use as potential and innovative therapeutic targets. The main approaches of modulating miRNA activity are the followings: (1) a miRNA mimic is a chemically created double-stranded RNA molecule, which imitates the endogenous miRNA (pre-miRNA) and binds to the complementary mRNA. The specific delivery to cardiac cells involves the use of viral vectors with high affinity to the myocardium [17]; (2) an antagomiR is a synthetic, single strand oligonucleotide that is complementary to a specific mature miRNA, and inhibits its action by binding with it [18]; (3) a miRNA sponge contains several sequences for a particular miRNA, and is capable to reduce the number of active miRNAs [8].

Summarizing the action of these molecules: they are replacing those miRNAs that are under-expressed and are silencing those over-expressed. In this regard, the first experimental data using antagomirs are promising in reverting cardiac fibrosis and hypertrophy $[19,20]$.

\section{Conclusions}

Molecular biology represents a new and potent tool in better understanding and more efficiently treating HF. miRNAs, a class of non-coding RNAs, have a proven role in many pathophysiological processes involved in the development of HF, and are almost ready to be used as diagnostic and prognostic biomarkers, and also, as therapeutic targets in HF, opening the way of a new paradigm in HF management.

\section{Authors' contribution}

István Adorján Szabó (Conceptualization; Methodology; Writing - original draft; Writing - review \& editing) Atilla Frigy (Conceptualization; Methodology; Resources; Supervision; Writing - original draft; Writing - review \& editing)

\section{Acknowledgement}

The article was elaborated as part of the Research Grant with private financing - nr.524/17.01.2017 of the University of Medicine, Pharmacy, Science and Technology of Tîrgu Mureș

\section{Conflict of interest}

None to declare.

\section{References}

1. Ponikowski P, Voors AA, Anker SD, Bueno H, Cleland JGF, Coats AJS, et al. - 2016 ESC Guidelines for the diagnosis and treatment of acute and chronic heart failure: The Task Force for the diagnosis and treatment of acute and chronic heart failure of the European Society of Cardiology (ESC). Developed with the special contribution of the Heart Failure Association (HFA) of the ESC. Eur Heart J. 2016;37(27):2129-2200

2. Morrow DA, de Lemos JA. Benchmarks for the assessment of cardiovascular biomarkers. Circulation. 2007;115(8):949-952

3. Correale M, Monaco I, Brunetti ND, di Biase M, Metra M, Nodari S, et al. Redefining biomarkers in heart failure. 2018;23(2):237-253

4. laconetti C, Gareri C, Polimeni A, Indolfi C. Non-Coding RNAs: The "Dark Matter" of Cardiovascular Pathophysiology. Int J Mol Sci. 2013;14(10):19987-20018

5. Islas JF, Moreno-Cuevas JE. A MicroRNA Perspective on Cardiovascular Development and Diseases: An Update. Int J Mol Sci. 2018;19(7):20752090

6. Tian J, An X, Niu L. Role of microRNAs in cardiac development and disease. Exp Ther Med. 2017;13(1):3-8

7. Sárközy M, Kahán Zs, and Csont T. A myriad of roles of miR-25 in health and disease. Oncotarget. 2018;9(30):21580-21612

8. Wojciechowska A, Braniewska A, Kozar-Kamińska K. MicroRNA in cardiovascular biology and disease. Adv Clin Exp Med. 2017;26(5):865874

9. Wang J, Liew OW, Chen Y-T. Overview of MicroRNAs in Cardiac Hypertrophy, Fibrosis, and Apoptosis. Int J Mol Sci. 2016;17(5):749-770

10. de Gonzalo-Calvo D, Iglesias-Gutiérrez E, Llorente-Cortés V. Epigenetic Biomarkers and Cardiovascular Disease: Circulating MicroRNAs. Rev Esp Cardiol (Engl Ed). 2017;70(9):763-769

11. Schulte C, Karakas M, Zeller T. microRNAs in cardiovascular disease clinical application. Clin Chem Lab Med. 2017;55(5):687-704

12. Yan H, Ma F, Li Y, Zhangv Y, Wang C, Qiu D. miRNAs as biomarkers for diagnosis of heart failure. Medicine. 2017;96(22):22-32

13. Marfella R, Di Filippo C, Potenza N, Sardu C, Rizzo MR, Siniscalchi M. Circulating microRNA changes in heart failure patients treated with cardiac resynchronization therapy: responders vs. non-responders. Eur $\mathrm{J}$ of Heart Fail. 2013;15(11):1277-1288

14. Tijsen AJ, Creemers EE, Moerland PD, de Windt LJ, Kok WE, Pinto YM. MiR423-5p As a Circulating Biomarker for Heart Failure. Circ Res. 2010;106(6):1035-1039

15. Schmitter D, Voors AA, van der Harst P. HFpEF vs. HFrEF: can microRNAs advance the diagnosis? Eur J of Heart Fail. 2015;17(4):351354

16. Nair N, Gupta S, Collier IX, Gongora E, Vijayaraghavan K. Can microRNAs emerge as biomarkers in distinguishing HFpEF versus HFrEF? Int. J. of Cardiology 2014;175(3):395-399

17. Oliveira-Carvalho V, Carvalho VO, Silva MM, Guimarães GV, Bocchi EA. MicroRNAs: a new paradigm in the treatment and diagnosis of heart failure? Arq Bras Cardiol. 2012;98(4):362-369

18. Krützfeldt J, Rajewsky N, Braich R, Rajeev KG, Tuschl T, Manoharan $\mathrm{M}$, et al. Silencing of microRNAs in vivo with 'antagomirs'. Nature. 2005;438(7068):685-689.

19. Thum T, Gross C, Fiedler J, Fischer T, Kissler S, Bussen M, et al. MicroRNA-21 contributes to myocardial disease by stimulating MAP kinase signalling in fibroblasts. Nature. 2008;456(7224):980-984

20. Montgomery RL, Hullinger TG, Semus HM, Dickinson BA, Seto AG, Lynch JM, et al. Therapeutic inhibition of miR-208a improves cardiac function and survival during heart failure. Circulation. 2011;124(14):15371547 